\title{
A comparative study of hysteroscopy and transvaginal ultrasonography in diagnosis of endometrial pathology in abnormal uterine bleeding
}

\author{
Guntupalli R. Swathi ${ }^{1}$, Madhu K. Nataraja ${ }^{2 *}$, Shukla S. Shetty ${ }^{2}$
}

\begin{abstract}
${ }^{1}$ Department of Obstetrics and Gynecology, Guntur Medical College, Kanna Vari Thota, Guntur, Andhra Pradesh, India

${ }^{2}$ Department of Obstetrics and Gynecology, JJM Medical College, Davangere, Karnataka, India
\end{abstract}

Received: 13 January 2020

Revised: 29 March 2020

Accepted: 04 April 2020

\section{*Correspondence:}

Dr. Madhu K. Nataraja,

E-mail: madhukn_5@yahoo.com

Copyright: ( ) the author(s), publisher and licensee Medip Academy. This is an open-access article distributed under the terms of the Creative Commons Attribution Non-Commercial License, which permits unrestricted non-commercial use, distribution, and reproduction in any medium, provided the original work is properly cited.

\section{ABSTRACT}

Background: Abnormal uterine bleeding is the most common complaint in gynaecology and an important source of morbidity. The ideal diagnostic tool to determine the cause for the same continues to be debated. Objective of this study was to compare accuracy of hysteroscopy and transvaginal sonography in diagnosis of endometrial pathology in abnormal uterine bleeding.

Methods: A total 100 women attending gynaecological outpatient in hospital attached to J. J. M. Medical College, Davangere with abnormal uterine bleeding fitting into the inclusion criteria during November 2014 to August 2016, were admitted and evaluated with Transvaginal sonography (TVS) and hysteroscopy. Data was collected and analysed.

Results: Among 100 patients of AUB in this study, majority of the patients were in perimenopausal age group. Menorrhagia is the most common presentation (45\%) followed by postmenopausal bleeding (20\%). Anaemia was detected in $79 \%$ of patients. Hysteroscopy was taken as gold standard and TVS findings were compared. The sensitivity of TVS in detecting polyps, submucous fibroid were $22.2 \%, 11 \%$ respectively and for the normal variants like proliferative and secretory it was $50 \%$ and $79.2 \%$ respectively. TVS showed good correlation with hysteroscope findings for normal variants of endometrium, but poor correlation for intracavitary pathologies.

Conclusions: Hysteroscopy is a rapid, safe, well tolerated and highly accurate means of diagnosing the cause of abnormal uterine bleeding in perimenopausal age group. Thus, it is advised as a first line investigation in evaluation of AUB.

Keywords: Abnormal uterine bleeding, Hysteroscopy, Menorrhagia, Transvaginal sonography

\section{INTRODUCTION}

Abnormal uterine bleeding (AUB), defined by bleeding occurring outside of normal cyclic menstruation that includes change in regularity, frequency of menses, duration or amount of bleeding during or in between periods. ${ }^{1}$ It is one of the most common gynaecological problem that health care providers face, accounting for 9$14 \%$ from menarche to menopause. ${ }^{2}$ In India, the reported prevalence is $17.9 \% .^{3}$ This proportion rises to $50 \%$ when perimenopausal and postmenopausal age groups are considered. It not only affects the quality of life such as intimate relationships, day-to-day living but can have serious adverse consequences such as anaemia, underlying malignancy or increased financial burdens. ${ }^{2}$ The International federation of gynecology and obstetrics working group on menstrual disorders has proposed a classification system (PALM-COEIN) for causes of the 
AUB in women. ${ }^{4}$ The categories of PALM group (polyp, adenomyosis, leiomyoma, malignancy and hyperplasia) are discrete structural entities that can be defined by imaging and/ or by histopathology, whereas those in the COEIN group (coagulopathy, ovulatory disorders, endometrial, iatrogenic and non-classified) represent nonstructural causes that cannot be defined by these techniques. The broad range of normal variation in menstrual bleeding causes difficulty in identifying abnormal patterns. The problem is that uterine bleeding has a wide range of diagnostic possibilities. Goals of clinical management are primarily dependent upon attaining a correct etiological diagnosis. Diagnostic evaluation includes investigations ranging from $\mathrm{CBC}$, hormonal assays, traditional dilatation and curettage, office based endometrial biopsy to pelvic ultrasonography for evaluation of endometrial/myometrial pathology contributing to the presentation.

Transvaginal sonography (TVS) is an inexpensive noninvasive modality permitting the use of higher frequency ultrasound waves at greater proximity to the uterus with no need for anaesthesia which is the recommended first line diagnostic tool for assessing uterine pathology in women presenting with AUB. ${ }^{5,6}$ It is considered a natural extension of the bimanual pelvic examination by many gynaecologists. It clearly depicts the uterine contour, echotexture, the status of ovaries and evaluates the endometrium in terms of thickness and its ovulatory and hormonal status.

Hysteroscopy has ushered a new era in the evaluation of abnormal uterine bleeding. It is easy to perform and widely available in study setup. By direct visualization of the uterine cavity it is possible to pin point the etiology in the majority of the cases. It can accurately detect endometrial hyperplasia and aids in the early diagnosis of endometrial carcinoma, uterine polyps and submucosal myoma. ${ }^{7,8}$ It is recommended to further evaluate the endometrium in women with abnormal bleeding when the endometrial echo is normal on TVS. ${ }^{9}$ This study has been taken up to analyse the place of hysteroscopy and TVS in the evaluation of abnormal uterine bleeding and to corelate hysteroscopic with that of TVS findings which help in provisional/final diagnosis. It also aims to correlate hysteroscopic findings with histopathological results.

\section{Objectives}

- To study the etiology of abnormal uterine bleeding and the significance of hysteroscopy and TVS in evaluation of the etiopathogenic factors.

- Correlating the diagnosis after transvaginal sonography and hysteroscopy.

\section{METHODS}

With a level IV evidence, a prospective cohort study was performed from September 2014 to August 2016 in the department of obstetrics and gynaecology, Bapuji hospital, Chigateri Government General Hospital and Women and Child Health Hospital attached to JJM Medical College, Davangere, Karnataka, India. The patients for this study were recruited by convenient sampling technique. A total of 100 abnormal uterine bleeding women who satisfied the inclusion and exclusion criteria were taken for the study.

All patients with age greater than 35 years with complaint of AUB were taken for the study. Patients with pregnancy, pelvic inflammatory disease, systemic causes of bleeding, vaginal or cervical causes of bleeding, thyroid disorders and coagulation disorders and unmarried girls were excluded from the study.

After informed written consent and counselling, detailed clinical history was taken. Obstetrical history included parity, mode of delivery, abortions and contraceptive use; detailed menstrual history regarding the cycle length, no of days of flow, type and amount of abnormal bleeding and duration of complaint and any relevant preceding events like IUCD insertion or abortion was taken. Per speculum examination was done to rule out cervical and vaginal causes and PAP smear was taken. Per vaginal examination was done to find out any uterine, cervical or adnexal pathology. Investigations like complete hemogram, bleeding time, clotting time, thyroid function tests, blood sugar, liver and kidney function tests and pregnancy test were carried out. Transvaginal sonography was done by $7.5 \mathrm{MHz}$ transducer and uterine size and contour, intramural and submucosal lesion and endometrial thickness were studied. Then diagnostic hysteroscopy was carried out for all patients under general anesthesia using $6 \mathrm{~mm}$ diagnostic sheath and 4 $\mathrm{mm}$ telescope. A systematic evaluation of the cavity was done observing the uterine cavity, fundus, tubal ostia, anterior and posterior uterine wall and cervical canal and biopsy taken for histopathological study which was considered as gold standard. After tabulating the findings of TVS and hysteroscopy it was compared with histopathology and the sensitivity, specificity, PPV and NPV of TVS was calculated and compared to hysteroscopy.

\section{Statistical analysis}

The analytical statistics were evaluated statistically with IBM SPSS statistics for windows, version 24.0, IBM Corp, Chicago, IL.

\section{RESULTS}

A total of 100 patients presenting with AUB who met the inclusion criteria were studied by TVS and hysteroscopy and evaluated between the year 2014 to 2016.

The most common age group was 35-39 years (33\%), followed by $45-49$ years $(25 \%)$ and $40-44$ years $(21 \%)$ with youngest being 36 and the eldest being 64 . The 
mean (SD) age of study participants was 44.5 (7.7) years. Most of the patients were multi parous (85\%), followed by primipara $(8 \%)$ and nullipara $(7 \%)$. The most common pattern of AUB was menorrhagia in $45 \%$ cases followed by postmenopausal bleeding in $20 \%$. The other symptoms were polymenorrhagia (12\%), polymenorrhoea (9\%), menometrorrhagia (6\%), hypomenorrhea and oligomenorrhoea (4\% each) (as shown in Figure 1). 58\% patients had dysmenorrhoea. Majority of the patients (68\%) were using some form of contraceptive at the time of their evaluation for AUB. 61\% were tubectomized, 5\% were using intrauterine contraceptive device (IUCD) and $2 \%$ were on oral contraceptive pills. A total of $79 \%$ patients were anaemic and $21 \%$ patients were with normal $\mathrm{Hb}$ levels in this study.

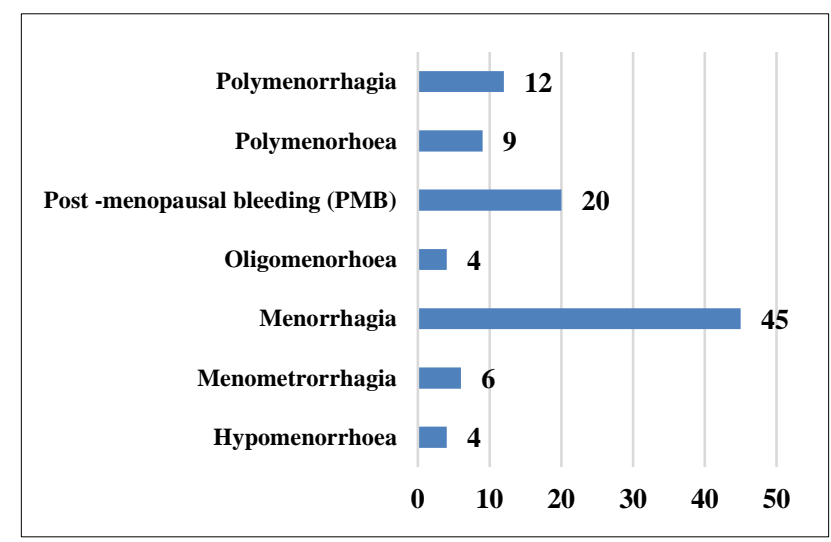

Figure 1: Distribution of symptoms in the study population.

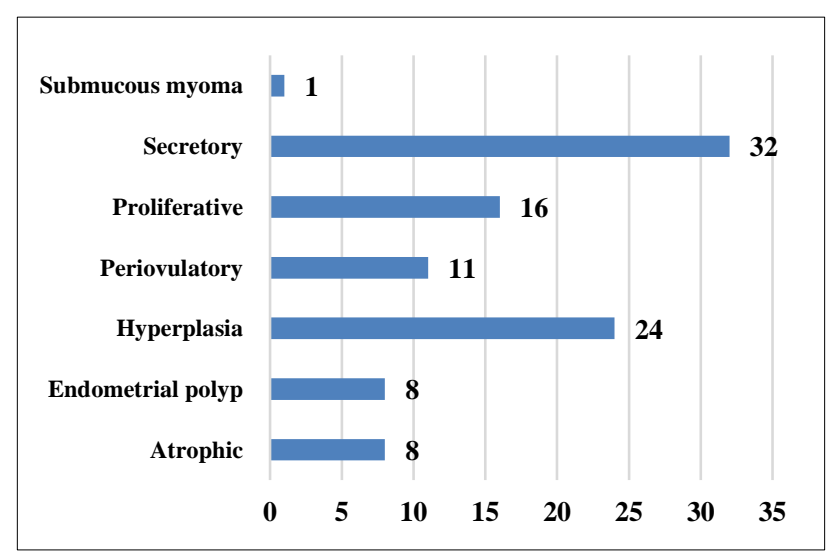

Figure 2: Distribution of study participants by TVS findings.

TVS was normal in 59\% patients. Among the abnormal findings, most common abnormality was endometrial hyperplasia $(24 \%)$, followed by endometrial polyp ( $8 \%$ ) and atrophic endometrium (8\%). Least common was submucous fibroid (1\%) (as shown in Figure 2).

Hysteroscopy was normal in $37 \%$ of cases. Among the abnormal ones, most common finding was endometrial hyperplasia seen in $20 \%$ cases followed by polyp in $18 \%$ cases, atrophic endometrium in $11 \%$, submucous fibroid in $9 \%$, endometrial carcinoma in $3 \%$ and intra-uterine synechiae in $2 \%$ (as shown in Figure 3 ).

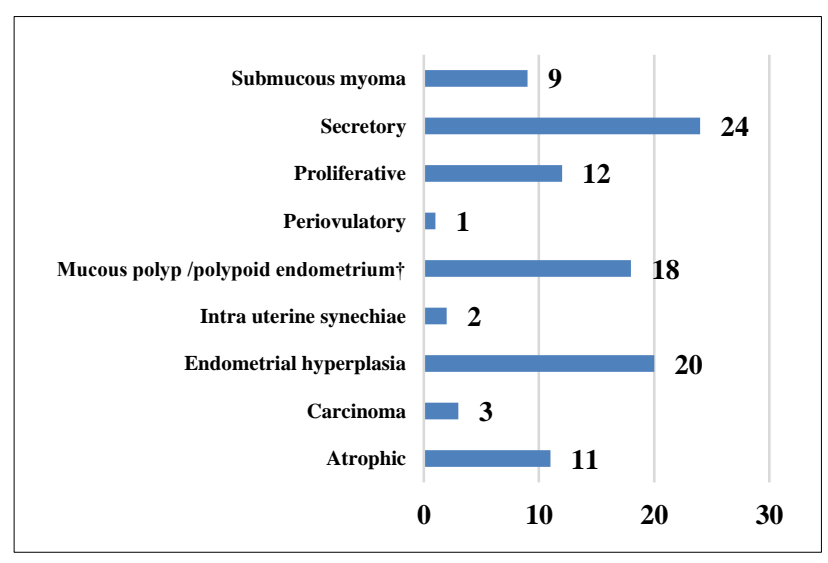

Figure 3: Distribution of study participants by hysteroscopy findings.

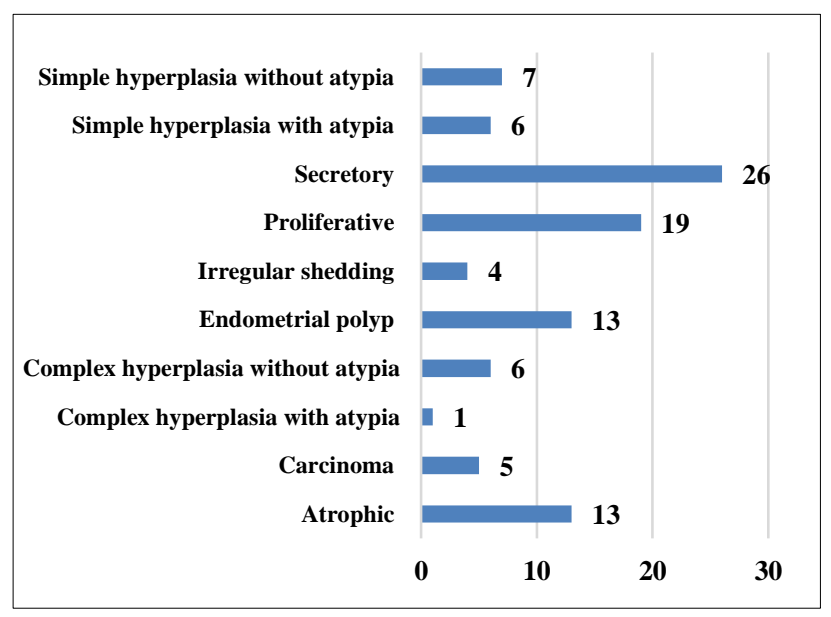

Figure 4: Distribution of study participants by findings of histopathological examination.

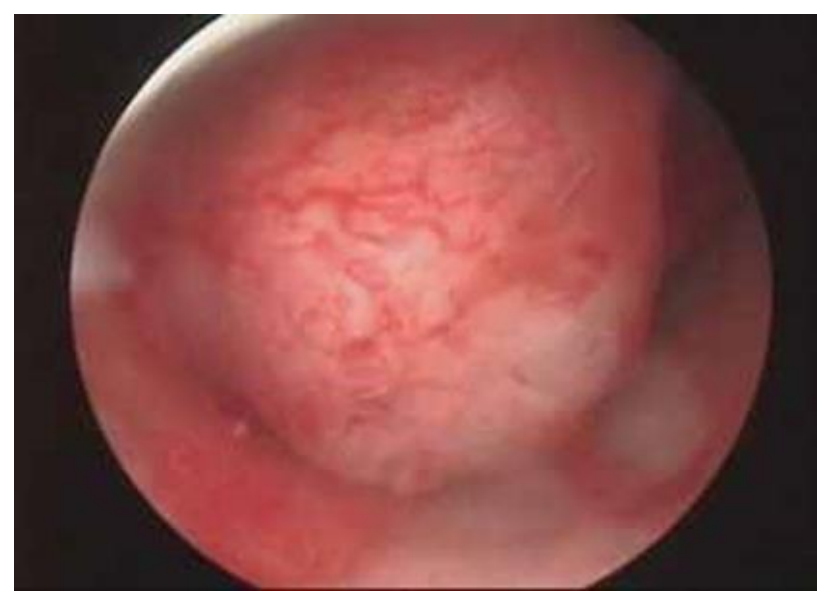

Figure 5: Submucosal fibroid.

Samples taken on hysteroscopy were analysed by histopathological examination. The histopathology 
showed normal endometrium in $45 \%$ cases. Hyperplasia was seen in 20 cases followed by 13 cases each of endometrial polyp and atrophic endometrium and 5 cases of endometrial carcinoma (as shown in Figure 4).

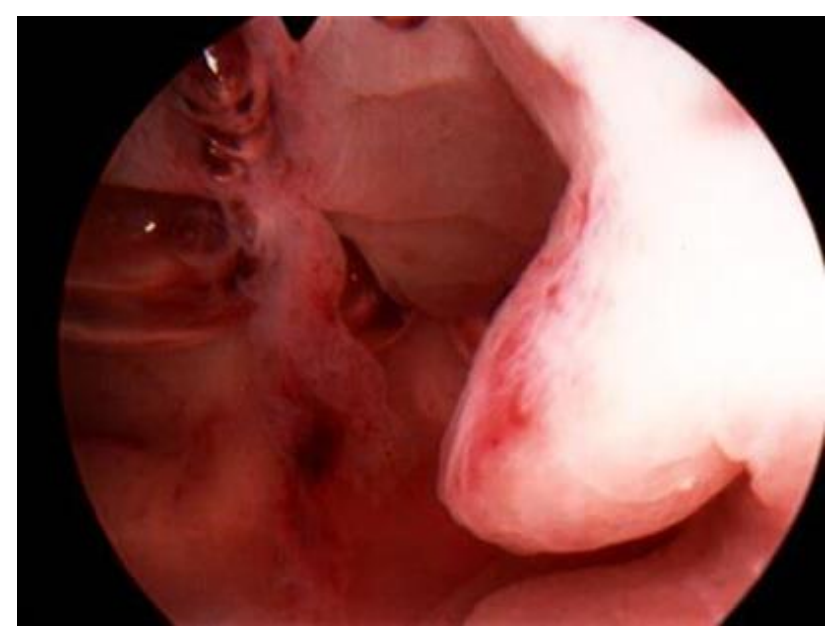

Figure 6: Mucosal polyp.

TVS has showed atrophic endometrium in 8 cases whereas 11 patients had atrophic endometrium on hysteroscopy, so TVS has missed 3 cases of atrophic endometrium. TVS has diagnosed only one patient of submucous fibroid while hysteroscopy diagnoses 9 such cases (Figure 5), TVS has diagnosed 8 cases of polyp while hysteroscopy diagnoses 18 such cases (Figure 6).

Hysteroscopy has diagnosed intra uterine synechiae in 2 cases (Figure 7) whereas TVS has missed both of them. Thus, intracavitary abnormalities like polyp, submucous fibroid, synechiae were better diagnosed with hysteroscopy (as shown in Table 1 and 2).

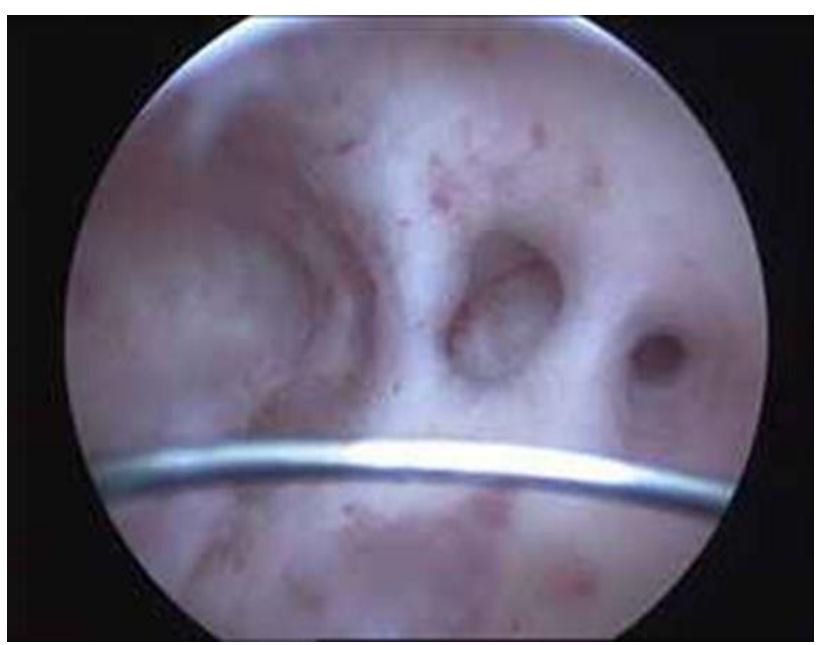

Figure 7: Intrauterine synechiae.

Table 1: Diagnostic accuracy of TVS compared to hysteroscopy.

\begin{tabular}{|lllllllllll|l|}
\hline Finding & TP & FP & FN & TN & Sensitivity & Specificity & PPV & NPV & Accuracy & p value \\
\hline Atrophic & 8 & 0 & 3 & 89 & 72.7 & 100 & 100 & 96.7 & 97 & $<0.001$ \\
\hline Proliferative & 6 & 10 & 6 & 78 & 50 & 88.6 & 37.5 & 92.9 & 84 & 0.004 \\
\hline Periovulatory & 1 & 10 & 0 & 89 & 100 & 89.9 & 9.1 & 100 & 90 & 0.01 \\
\hline Secretory & 19 & 13 & 5 & 63 & 79.2 & 82.3 & 59.4 & 92.3 & 82 & $<0.001$ \\
\hline Hyperplasia & 10 & 14 & 10 & 66 & 50 & 82.5 & 41.7 & 86.8 & 76 & 0.005 \\
\hline Polyp & 4 & 4 & 14 & 78 & 22.2 & 95.1 & 50.0 & 84.8 & 82 & 0.04 \\
\hline Submucous myoma & 1 & 0 & 8 & 91 & 11.1 & 100 & 100 & 91.9 & 92 & 0.008 \\
\hline Carcinoma & 0 & 0 & 3 & 97 & 0 & 100 & - & 97 & 97 & 0.04 \\
\hline Intra uterine synechiae & 0 & 0 & 2 & 98 & 0 & 100 & - & 98 & 98 & 0.03 \\
\hline
\end{tabular}

Table 2: Comparison of findings of hysteroscopy and transvaginal sonography.

\begin{tabular}{|c|c|}
\hline Hysteroscopy (n=100) & Transvaginal sonography $(\mathrm{n}=100)$ \\
\hline \multirow{3}{*}{ Atrophic $(n=11)$} & Atrophic $(n=8)$ \\
\hline & Proliferative $(n=2)$ \\
\hline & Hyperplasia $(n=1)$ \\
\hline \multirow{3}{*}{ Proliferative $(n=12)$} & Proliferative $(n=6)$ \\
\hline & Endometrial polyp $(n=2)$ \\
\hline & Secretory $(n=4)$ \\
\hline \multirow{3}{*}{ Secretory $(n=24)$} & Hyperplasia $(n=4)$ \\
\hline & Secretory $(n=19)$ \\
\hline & Proliferative $(n=1)$ \\
\hline Periovulatory $(\mathrm{n}=1)$ & Periovulatory $(\mathrm{n}=1)$ \\
\hline \multirow{3}{*}{ Hyperplasia (n=20) } & Secretory $(n=4)$ \\
\hline & Hyperplasia $(n=10)$ \\
\hline & Proliferative $(n=4)$ \\
\hline
\end{tabular}




\begin{tabular}{|c|c|}
\hline Hysteroscopy (n=100) & Transvaginal sonography $(\mathrm{n}=100)$ \\
\hline & Periovulatory $(\mathrm{n}=1)$ \\
\hline & Endometrial polyp $(\mathrm{n}=1)$ \\
\hline \multirow{4}{*}{ Polyp/polypoid endometrium $(\mathrm{n}=18)$} & Periovulatory $(\mathrm{n}=8)$ \\
\hline & Secretory $(\mathrm{n}=2)$ \\
\hline & $\begin{array}{l}\text { Hyperplasia }(n=3) \\
\text { Endometrial polyp }(n=4)\end{array}$ \\
\hline & Proliferative $(\mathrm{n}=1)$ \\
\hline \multirow{2}{*}{ Carcinoma $(\mathrm{n}=3)$} & Periovulatory $(\mathrm{n}=1)$ \\
\hline & Hyperplasia $(n=2)$ \\
\hline Intrauterine synechiae $(\mathrm{n}=2)$ & Secretory $(n=2)$ \\
\hline \multirow{5}{*}{ Submucous myoma (n=9) } & Submucous myoma $(\mathrm{n}=1)$ \\
\hline & Secretory $(n=1)$ \\
\hline & Endometrial polyp $(n=1)$ \\
\hline & Proliferative $(n=2)$ \\
\hline & Hyperplasia $(n=4)$ \\
\hline
\end{tabular}

\section{DISCUSSION}

In cases with AUB, the methods available for evaluation of the uterine cavity and endometrial pathology have developed considerably over the last few years. Transvaginal sonography is considered a simple examination with good accuracy. The uterus and its pathological lesions can be visualized clearly but there are conflicting reports about its diagnostic accuracy. Hysteroscopy has the advantage of providing a direct visualization of the uterine cavity and endometrium and allows biopsy to be taken from suspected abnormalities.

\section{Distribution according to age}

In this study, the mean age of the patients was 44.5 years, which correlates with studies of Vercellini $\mathrm{P}$ et al with average age as $41.5 \pm 7.8$ years and Vitner $D$ et al with $41.8 \pm 13.49$ years. ${ }^{10,11}$ Most common age group having AUB in this study were in between 35-39 years (33\%), followed by $45-49$ years $(25 \%)$ and $40-44$ years $(21 \%)$ which means majority of the patients belonged to perimenopausal age group. Similarly, Mishra S et al had maximum number of AUB patients in age group 36-40 years $(39.2 \%)$ followed by $27.5 \%$ women in $41-45$ years age group. ${ }^{12}$ As per Kumari $\mathrm{M}$ et al and Patil R et al $37 \%$ and $45 \%$ patients respectively were in $31-40$ years age group. ${ }^{13,14}$ Emanuel MH et al, Sheth SS, Towbin NA et al and Veena BT et al also had similar clinical presentation in their studies. ${ }^{6,15-17}$

\section{Distribution according to parity}

In this study, most of the patients were multiparous contributing $85 \%, 8 \%$ primipara, $7 \%$ nulliparous which correlates with study of Mishra $\mathrm{S}$ et al with $65 \%$ multiparous, $30 \%$ primiparous and $5 \%$ nulliparous. ${ }^{12}$ As per Kumari $\mathrm{M}$ et al and Patil $\mathrm{R}$ et al, $61 \%$ and $71 \%$ patients with AUB were multiparous respectively. ${ }^{13,14}$

\section{Distribution according to bleeding pattern}

In this study, most common presentation was menorrhagia found in $45 \%$ cases followed by postmenopausal bleeding in $20 \%$ cases, which was comparable to the study by Mishra $\mathrm{S}$ et al (menorrhagia $(45 \%)$ ), Kumari $\mathrm{M}$ et al. $^{12,13}$ (39\% incidence of menorrhagia), Tahir et al (40\%), Pillai S et al (46.5\%) Shobhitha et al (40\% in patients of reproductive age), Veena BT et al (28\%). ${ }^{17-20}$ Other bleeding patterns in present study are polymenorrhagia (12\%), polymenorrhoea (9\%), menometrorrhagia (6\%), hypomenorrhoea and oligomenorrhoea (4\% each).

Most of the patients in the study were anaemic contributing almost 79\%, which correlates with studies of Emanuel et al (59.3\%), Sheth SS (73\%), Sabherwal G $(65 \%){ }^{6,15,21}$

\section{Distribution according to TVS finding}

In this study TVS showed normal uterus in 59\% case and abnormal in $41 \%$ cases which correlates with Paolo Vercellini et al where normal cases in 39\% and abnormal in 54\% and with Towbin et al where TVS showed 59\% normal uterus. ${ }^{10,16}$ In this study, most common abnormality was endometrial hyperplasia (24\%), followed by endometrial polyp (8\%) and atrophic endometrium (8\%). Least common was submucous fibroid $(1 \%)$. This was in contrast to study done by Mishra $\mathrm{S}$ et al, which concluded that most common uterine pathology detected by USG was fibroid (18.3\% cases) followed by adenomyosis (10\%), polyp (7.5\%) and thickened endometrium (5\%) as a cause of AUB. ${ }^{12}$ Also, Kumari $\mathrm{M}$ et al showed most common anomaly detected to be fibroids $(14.28 \%) .{ }^{13}$ Others were thickened endometrium (11.4\%), adenomyosis (8.57\%), polyp $(8.57 \%)$, normal uterus with polycystic ovaries in $2.8 \%$. 


\section{Hysteroscopy in detection of cause of AUB}

Hysteroscopy in the present study showed normal uterus in $37 \%$ cases and abnormal in $63 \%$ cases. Among the abnormal ones, most common finding was endometrial hyperplasia seen in $20 \%$ cases, followed by polyp in $18 \%$ cases, atrophic endometrium in $11 \%$, submucous fibroid in $9 \%$, endometrial carcinoma in $3 \%$ and intra-uterine synechiae in $2 \%$. Mishra $\mathrm{S}$ et al, showed intrauterine pathology in 21 cases. $^{12}$ Polyp was found in 18 (15\% of cases) and submucosal fibroid in 3 (2.5\% of cases). Similar pattern was observed in studies done by Gunjan et al, Veena A et al and Veena BT et al and Neumann T et al. ${ }^{17,21-23}$

\section{Detection of cause of AUB by TVS}

Sensitivity and specificity of the intra-uterine pathologies by TVS were correlating with other studies (as shown in Table 3 and 4).

Table 3: Comparison of diagnostic accuracy of polyps in other studies.

\begin{tabular}{|lll|}
\hline Polyps & Sensitivity & Specificity \\
\hline Vitner D et al $^{11}$ & $44.5 \%$ & $81.8 \%$ \\
\hline Veena BT et al $^{17}$ & $22 \%$ & $100 \%$ \\
\hline Present study & $22.2 \%$ & $95 \%$ \\
\hline
\end{tabular}

Table 4: Comparison of diagnostic accuracy of atrophic endometrium in other studies.

\begin{tabular}{|llll|}
\hline $\begin{array}{l}\text { Atrophic } \\
\text { endometrium }\end{array}$ & Sensitivity & Specificity & Accuracy \\
\hline Veena BT ${ }^{17}$ & 60 & 96 & 90 \\
\hline Present study & 72.7 & 100 & 82 \\
\hline
\end{tabular}

Table 5: When compared for normal variants TVS showed good accuracy.

\begin{tabular}{|lll|}
\hline Normal variants TVS & Veena BT $^{\mathbf{1 7}}$ & Present study \\
\hline Proliferative & 83 & 84 \\
\hline Secretory & 66 & 82 \\
\hline
\end{tabular}

So, TVS showed good accuracy in diagnosing normal variants and poor in diagnosing intracavitary pathologies (Table 5). In the present study, there were 2 cases of intrauterine synechiae diagnosed by hysteroscopy but missed by TVS, similar findings were observed in Veena BT et al. ${ }^{17}$

TVS and hysteroscopy should be employed hand in hand in evaluation of AUB after assessing the need and affordability of patient.

\section{CONCLUSION}

Most of the patients presenting with AUB are in perimenopausal group. There is a high incidence of intrauterine pathologies in this age group. Both TVS and hysteroscopy will diagnose the conditions with different accuracies. Compared to TVS, hysteroscopy allows for a direct visualisation of the endometrial cavity and offers additional opportunity of obtaining a directed biopsy if needed.

Hysteroscopy is a rapid, safe, well tolerated and highly accurate means of diagnosing the cause of excessive uterine bleeding. It permits patient and physician to discuss more treatment options before surgery, which means savings in time, in drug, procedure, professional and hospital costs.

\section{Funding: No funding sources}

Conflict of interest: None declared

Ethical approval: The study was approved by the Institutional Ethics Committee

\section{REFERENCES}

1. Vilos GA, Tureanu V, Garcia M, Abu-Rafea B. The levonorgestrel intrauterine system is an effective treatment in women with abnormal uterine bleeding and anticoagulant therapy. J Minim Invasive Gynecol. 2009;16(4):480-4.

2. Fraser IS, Langham S, Uhl-Hochgraeber K. Healthrelated quality of life and economic burden of abnormal uterine bleeding. Expert Rev Obstet Gynecol. 2009;4(2):179-89.

3. Sharma A, Dogra Y. Trends of AUB in tertiary centre of Shimla hills. J Midlife health. 2013;4:67-8.

4. Munro MG, Critchley HO, Fraser IS. FIGO menstrual disorders working group. The FIGO classification of causes of abnormal uterine bleeding in the reproductive years. Fertil Steril. 2011;95(7):2204-8.

5. Dijkhuizen FP, Brolmann HA, Potters AE, Bongers MY, Heinz AP. The accuracy of transvaginal ultrasonography in the diagnosis of endometrial abnormalities. Obstet Gynecol. 1996;87:345-9.

6. Emanuel MH, Verdel MJ, Wamsteker K, Lamemes FB. A prospective comparison of TVS and diagnostics hysteroscopy in the evaluation of patients with abnormal uterine bleeding. Clinical implications. AM J Obstet Gynaecol. 1995;172(4):547-52.

7. Baggish MS. Operative hysteroscopy. In: Rock JA, Jones HW III, editors. TeLinde's Operative Gynecology $9^{\text {th }}$ edition. Philadelphia: Lippincott Williams and Wilkins; 2003:379-411.

8. Taneja P, Duggal BS. Hysteroscopy: past, present and future. Med J Armed Force India. 2002;58:2934.

9. de Vries LD, Dijkhuizen FP, Mol BW, Brölmann HA, Moret E, Heintz AP. Comparison of transvaginal sonography, saline infusion sonography and hysteroscopy in premenopausal women with abnormal uterine bleeding. J Clin Ultrasound. 2000;28(5):217-23. 
10. Vercellini P, Cortesi I, Oldani. The role of transvaginal ultrasonography and outpatient diagnostic hysteroscopy in the evaluation of patients with menorrhagia. Hum Reprod. 1997;12:1768-71.

11. Dana V, Shlomo F, Israel G, Nizar K, Zeev W. Comparison between ultrasonography and hysteroscopy in the diagnosis of uterine bleeding. Eur J Obstet Gynaecol Reprod Biol. 2013;171:143-5.

12. Mishra S, Panda B. Efficacy of ultrasonography and hysteroscopy and their correlation with endometrial histopathology in a case of abnormal uterine bleeding in late reproductive age. Ann Int Med Den Res. 2018;4(5):OG10-OG14.

13. Kumari M, Gupta AS. Efficacy of USG and hysteroscopy in the evaluation of AUB. Int J Reprod Contracept Obst Gynecol. 2015;4(6):1926-35.

14. Patil R, Patil RK, Andola SK, Laheru V, Bhandar M. Histopathological spectrum of endometrium in dysfuctional uterine bleeding. Int J Biol Med Res. 2013;4(1):2798-801.

15. Sheth SS, Nehrukar NM, Mangeskar P. Hysteroscopy in abnormal bleeding. J Obstet Gynaec India. 1990;40(3):451-4.

16. Towbin N, Gviazada I, March C. Office hysteroscopy versus transvaginal ultrasonography in evaluation of patients with excessive uterine bleeding. AM J Obstet gynaecol. 1996;174:1678-82.

17. Veena BT, Nirmalashivalingaiah. Role of transvaginal sonography and diagnostic hysteroscopy in abnormal uterine bleeding. J Clin Diagn Res. 2014;8(12):6-8.

18. Tahir MM, Bigrigg MA, Browning JJ, Brookes ST, Smith PA. A randomised controlled trial comparing transvaginal ultrasound, outpatient hysteroscopy and endometrial biopsy with inpatient hysteroscopy and curettage. Br J Obstet Gynecol. 1999;106:1259-64.

19. Pillai SS. Sonographic and histopathological correlation and evaluation of endometrium in perimenopausal women with abnormal uterine bleeding. Int J Reprod Contracept Obstet Gynecol. 2014;3(1):113-7.

20. Shobhitha GL, Kumari VI, Priya PL, Sundari BT. Endometrial study by TVS and It's correlation with histopathology in abnormal uterine bleeding. J Dental Med Sci. 2015;14(4):21-32.

21. Sabherwal G, Bhasin S. Role of transvaginal sonography, diagnostic hysteroscopy and dilatation and curettage on cases of menorrhagia in the perimenopausal age group. J Obstet Gynaec India. 2002;55(3):106-8.

22. Veena A, Menta S, Randar A. Evaluation of dysfunctional uterine bleeding by TVS hysteroscopy and histopathology. J Obstet Gynecol. 2003;53:1707 .

23. Neumann T, Astudilo J. Hysteroscopy study in patients with abnormal uterine bleeding. J Obstet Gynecol. 1994;59(5):349-52.

Cite this article as: Swathi GR, Nataraja MK, Shetty SS. A comparative study of hysteroscopy and transvaginal ultrasonography in diagnosis of endometrial pathology in abnormal uterine bleeding. Int J Reprod Contracept Obstet Gynecol 2020;9:1772-8. 